To apply the method to lead stlphide ores it will be necessary to convert into the carbonate, ${ }^{1}$ dissolve in dilute nitric acid and peroxidize as directed above.

To our chief chemist, Mr. William Brady, the writer is indebted for valuable suggestions and for permission to publish this method.

LABORATORY OF ILLINOIS STEEL CO., Sovth Chicago, ILL.

\title{
THE PHOTOMETRIC DETERMINATION OF SULPHUR IN COAL.
}

By S. W. Parr aND C. H, MCClure.

Received July 20,3904 .

THE use of sodium peroxide as an oxidizing agent for the sulphur of coal has received considerable attention, but the violence of the reaction has brought disfavor upon the method. However, by means of a closed bomb, as in the Parr calorimeter, there has been fully demonstrated the practicability of using sodium peroxide for this purpose. Indeed, over two years ago Mr. Milton Hersey, of Montreal, Canada, in a communication to the author, reported the very satisfactory use of the residues from the calorimetric process for gravimetrically determining the sulphur. Later articles by Sundstrom ${ }^{2}$ and by von Konek $^{3}$ have advocated the same method.

Coupling the sodium peroxide method of arriving at a combustion with the photometric method proposed by Mr. Hinds, there seem to be possibilities well worth investigating.

The work with the photometer, however, either as outlined by Mr. Hinds, or as elaborated by Mr. Jackson, ${ }^{5}$ was not found satisfactory. A careful study was made of the variable elements that entered into the method. The method prescribed a candle of standard power, maintained at a definite distance from the bottom of the graduated tube in which was read the depth of liquid through which the outline of the candle flame could be seen. It was soon found that the strength of the light had little to do with the matter. A stronger light would illuminate the

1 Furman's "Manual of Practical Assaying," page 139.

2 This Journal, 25,184 .

3 Zischr, angeze. Chem., 190,3. p. 5I7.

4 This Journal. 23, 269.

i Ibid., 23, 799. 
licuid to a corresponding degree and cause the outline of the canclle flame to disappear at about the same depth as a lesser light with a less illumination of the liquid. As between a common candle and a forty candle-power acetrlene light there was no marked difference. Indeed, the greatest difference was noted when the diffused light was cut out by diaphragnns, in which case the light could be seen through a greater depth. An extreme illustration of this fact was afforded by completely blackening an incandescent light bulb and then cleaning a small spot to show a

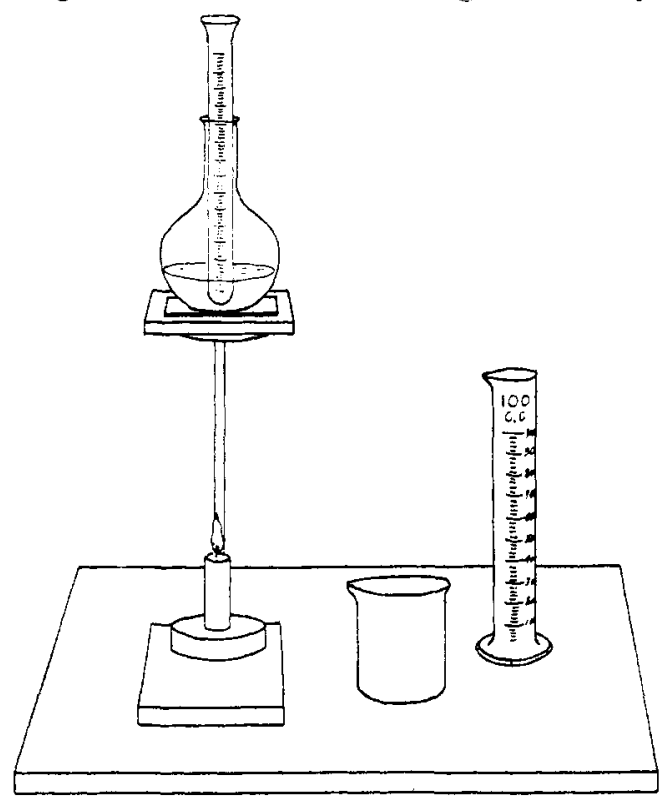

Photometer for Sulphur Determinations.

short length of the glowing filament. This bit of flament, which afforded no illumination to the liquid, could be seen through a very much greater depth than was the case with an ordinary candle, though its power was far below the standard. Other disturbing conditions related to the method of precipitation, whether hot or cold, whether the barium salt was added in the solid or the liquid state, whether readings were macle at once, or on standing, or whether precipitations made in the cold were subsequently heated or not. The control of the conditions regarding the light has been accomplished with a greatly modified apparatus in the following manner, as shown in Fig. I. 
The tube, graduated in millimeters, is placed in a common flask having a little clear water in the bottom. 'The flask is placed on a square of glass resting on a carbon plate about $5 / 8$ of an inch thick and having a $1 / 4$ inch hole in the center. The glass prevents the condensation of moisture on the bottom of the flask. The carbon plate is adjusted about io inches above the flame of a common candle. It will be noticed that the reading tube has a round bottom. This is carefully blown, of clear glass without flaw, and ground on the outer surface, the whole, when immersed, playing the part of a lens. By this arrangement, together with the diaphragm effect of the hole in the carbon plate, a pencil of light is secured with the minimum amount of illumination being imparted to the liquid. Moreover, instead of the varying and indefinite outline of a candle flame there appears a steady compact point of light. The end reading is thereby rendered sharp and definite. It is interesting to note that precipitations made with the barium salt in solution, or with the sulphate solution hot, transmit the rays from the candle as white light, while in the case of precipitations made with the crystals of the salt, the red rays only are transmitted, the illumination of the liquid is in this way still further reduced, and the sharpness of the end reading is thereby promoted. To secure concordant results, definiteness of precipitation must be obtained. This is accomplished by adding the barium salt to Ioo cc. of the slightly acid solution at room temperature, and after dissolving completely, heating on the waterbath to about $70^{\circ}$. Allow to stand for half an hour and bring to the room temperature, when it is ready to transfer to the photometric tube for reading. It is not necessary to detail the results of the large number of experiments for testing the variations due to temperature and time of standing before reading. The above conditions give the most constant results.

The conditions are purely empirical, but not arbitrary within reasonable limits, except as to the size of the hole through the plate and the method of precipitation.

It has been necessary to work out a new table. This has been developed directly from a standard solution of potassium sulphate having 0.5438 . gram dissolved in a liter, thus containing $0.000 \mathrm{I}$ gram of sulphur by weight per cubic centimeter of solution. Since eyes differ in their sensitiveness to light, a standard solu- 
TABIE I.

\begin{tabular}{|c|c|c|c|c|c|c|c|}
\hline \multicolumn{8}{|c|}{$\begin{array}{c}\text { PHOTOMETRIC TABLE FOR SULF } \\
\text { WEIGHT OF SULPHUR IN GRAMS } \\
\text { PER MILLIMETER DEPTH }\end{array}$} \\
\hline M.M. & $\begin{array}{l}\text { SULPHUR } \\
\text { IN GRAMS }\end{array}$ & M.M. & $\begin{array}{l}\text { SULPHUR } \\
\text { ING GRAMS }\end{array}$ & M.M. & $\begin{array}{l}\text { SULPHUR } \\
\text { IN GRAMS }\end{array}$ & M.M. & $\begin{array}{l}\text { SULPHUR } \\
\text { IN GRAMS }\end{array}$ \\
\hline 200 & 0.00138 & 151 & 0.00161 & 117 & 0.00204 & 83 & 0.00270 \\
\hline 195 & 0.00140 & 150 & 0.00162 & 116 & 0.00206 & 82 & 0.00273 \\
\hline 190 & 0.00142 & 149 & 0.00163 & 115 & 0.00208 & 81 & 0.00277 \\
\hline 185 & 0.00145 & 148 & 0.00164 & $1 / 4$ & 0.00210 & 80 & 0.00280 \\
\hline 183 & 0.00147 & 147 & 0.00165 & $1 / 3$ & 0.00212 & 79 & 0.00284 \\
\hline 180 & 0.00150 & 146 & 0.00166 & $1 / 2$ & 0.00214 & 78 & 0.00288 \\
\hline 179 & 0.00150 & 145 & 0.00167 & 111 & 0.00216 & 77 & 0.00292 \\
\hline 178 & 0.00151 & 144 & 0.00168 & 110 & 0.00218 & 76 & 0.00296 \\
\hline 177 & 0.00151 & 143 & 0.00169 & 109 & 0.00220 & 75 & 0.00300 \\
\hline 176 & 0.00151 & 142 & 0.00171 & 108 & 0.00222 & 74 & 0.00302 \\
\hline 175 & 0.00151 & 141 & 0.00172 & 107 & 0.00224 & 73 & 0.00304 \\
\hline 174 & 0.00152 & 140 & 0.00174 & 106 & 0.00226 & 72 & 0.00307 \\
\hline 173 & 0.00152 & 139 & 0.00175 & 105 & 0.00228 & 71 & 0.00310 \\
\hline 172 & 0.00152 & 138 & 0.00176 & 104 & 0.00230 & 70 & $0.003 / 3$ \\
\hline 171 & 0.00152 & 137 & 0.00177 & 103 & 0.00231 & 69 & $0.003 / 7$ \\
\hline 170 & 0.00153 & 136 & 0.00179 & 102 & 0.00233 & 68 & 0.00320 \\
\hline 169 & 0.00153 & 135 & 0.00180 & 101 & 0.00234 & 67 & 0.00323 \\
\hline 168 & 0.00153 & 134 & 0.00181 & 100 & 0.00236 & 66 & 0.00327 \\
\hline 167 & 0.00154 & 133 & 0.00182 & 99 & 0.00238 & 65 & 0.00330 \\
\hline 166 & 0.00154 & 132 & 0.00184 & 98 & 0.00239 & 64 & 0.00335 \\
\hline 165 & 0.00154 & 131 & 0.00185 & 97 & 0.00240 & 63 & 0.00340 \\
\hline 164 & 0.00155 & 130 & 0.00187 & 96 & 0.00241 & 62 & 0.00345 \\
\hline 163 & 0.00155 & 129 & 0.00188 & 95 & 0.00243 & 61 & 0.00350 \\
\hline 162 & 0.00155 & 128 & 0.00189 & 94 & 0.00244 & 60 & 0.00355 \\
\hline 161 & 0.00156 & 127 & 0.00190 & 93 & 0.00246 & 59 & 0.00360 \\
\hline 160 & 0.00156 & 126 & 0.00191 & 92 & 0.00248 & 58 & 0.00367 \\
\hline 159 & 0.00156 & 125 & 0.00193 & 91 & 0.00250 & 57 & 0.00373 \\
\hline 158 & 0.00157 & 124 & 0.00195 & 90 & 0.00252 & 56 & 0.00380 \\
\hline 157 & 0.00157 & 123 & 0.00196 & 89 & 0.00255 & 55 & 0.00386 \\
\hline 156 & 0.00158 & 122 & 0.00198 & 88 & 0.00257 & 54 & 0.00393 \\
\hline 155 & 0.00158 & 121 & 0.00199 & 87 & 0.00260 & 53 & 0.00400 \\
\hline 154 & 0.00159 & 120 & 0.00200 & 86 & 0.00262 & 52 & 0.00407 \\
\hline 153 & 0.00159 & 119 & 0.00201 & 85 & 0.00265 & 51 & $0.004 / 3$ \\
\hline 152 & 0.00160 & 118 & 0.00203 & 84 & 0.00267 & 50 & 0.00420 \\
\hline
\end{tabular}


tion should be prepared by which to check the table for the individual using it.

Table II.-Showing Percentages of Stlphur.

\begin{tabular}{|c|c|c|c|}
\hline & Illinois coal. Washit & $\begin{array}{l}\text { igs from Mahler } \\
\text { bomb. } \\
\text { Per cent.) }\end{array}$ & $\begin{array}{c}\text { Residues from Parr } \\
\text { calorimeter in photom- } \\
\text { eter. } \\
\text { (Per cent.) }\end{array}$ \\
\hline I & Odin, pea................ & 2.30 & 2.17 \\
\hline 2 & St. John's lump .......... & I.55 & 1.65 \\
\hline 3 & Pana, slack ............... & 4.03 & 4.04 \\
\hline 4 & Danville, lump............. & 2.16 & $2.3 \mathrm{I}$ \\
\hline 5 & Ridgely, pea $\ldots . . \ldots \ldots \ldots$ & $4 . \infty 0$ & 4.01 \\
\hline 6 & Bloomington, lump........ & 2.57 & 2.68 \\
\hline 7 & Spring Valley, washed...... & 3.04 & 3.20 \\
\hline 8 & Elmwood $\ldots \ldots \ldots \ldots \ldots \ldots$ & 1.53 & I.6I \\
\hline
\end{tabular}

Results from use of this method, as above outlined, in comparison with those obtained under standard conditions, are shown in Table II.

UNIVERSITY OF IILINOIS,

URBANA, ILL.

CONTRIBUTIONS FROM THE CHEMICAL LABORATORY OF THE UNIVERSITY OF MICHIGAN.]

\section{FURTHER EXPERIMENTS ON THE CLINKERING OF PORT- LAND CEMENT AND ON THE TEMPERATURE OF FORMATION OF SOME OF THE CONSTITUENTS. ${ }^{1}$}

By EDWard DEMILLe CaMpBell.

THIS work is, in a way, a continuation of the results published by the author in this Journal $(24,248,969 ; 25,1103)$, and the experiments have been largely suggested by the results of the work previously reported.

In a paper entitled "An Experiment upon the Influence of the Fineness of Grinding upon the Clinkering of Portland Cement" 25, IIO3), the author, with S. Ball, described the progress of linkering in a raw mixture used by a prominent eastern cement mill. This raw mixture was burned in the laboratory rotary ement kiln, employed for our previous experiments. Two experiments, IO4 and 105, were made with this same raw maerial. In Experiment I04 the raw mixture was burned without

1 The laboratory work in the experiments to be described in this paper has been done diring the present year by Messrs. E. E. Ware, D. H. Clary, and M. G. Doll, to whom I ish here to acknowledge my indebtedness for the care with which the work has been one. 